\title{
CHEMICAL REACTION CYCLES FOR THE RECOVERY OF LOW-LEVEL THERMAL ENERGY
}

\author{
ShigetaKa FUJII, Hideo KAMEYAMA, Kunio YOSHIDA \\ AND DAIZO KUNII \\ Department of Chemical Engineering, University of Tokyo, \\ Tokyo 113
}

\begin{abstract}
At present, much thermal energy exhausted from industrial processes has been unrecoverably lost. In this paper a new method, a chemical heat pump is proposed for recovering such lowlevel energy by use of chemical reaction cycles. Through this method the low-level energy can be converted to higher and more useful energy. Thermodynamical study of this method and the practical example, Triangle Process 1, 2 and 3 are described.
\end{abstract}

\section{Introduction}

The world is turning from consumption to conservation as the industrialized nations find it more difficult and expensive to continue their past rates of energy utilization. In particular, Japan must enhance the improvement of utilization of its conventional energy sources in parallel with the development of new energy resources because it is facing serious problems of both energy shortage and pollution. In fact, however, industrial processes exhaust a large amount of thermal energy in forms of water or gas when its temperature is very low. In the steelmaking industry, for example, total amount of $4 \times 10^{12} \mathrm{kcal}$ has been unrecoverably wasted every year, but $45 \%$ of this thermal energy is remarkably occupied by exhaust water or gas of which the temperature is below $200^{\circ} \mathrm{C}^{3}$. For the purpose of recovering such a low-level thermal energy, freon-turbine, heat-pump etc. have been proposed and developed so far. But they are still economically non-attractive due to low efficiencies and high costs. In this paper, therefore, an entirely new method for recovering low-level energy is proposed. This "chemical heat pump" will be able to pump up again low-level thermal energy to high levels by use of chemical reaction cycles. This method may offer a promising way for more efficient use of energy in industrial processes.

\section{Chemical Heat Pump}

First consider a two-step closed cycle in which a reaction proceeds endothermically and the reverse

\footnotetext{
Received October 7, 1976. Correspondence concerning this article should be addressed to $\mathrm{K}$. Yoshida.
}

reaction proceeds exothermically with help of catalysts. An example of this kind is the EVA-ADAM system ${ }^{5}$ expressed as

EVA: $\quad \mathrm{CH}_{4}+\mathrm{H}_{2} \mathrm{O} \rightarrow \mathrm{CO}+3 \mathrm{H}_{2}, \Delta H=50$

ADAM: $\mathrm{CO}+3 \mathrm{H}_{2} \rightarrow \mathrm{CH}_{4}+\mathrm{H}_{2} \mathrm{O}, \Delta H=-50$ [kcal/g-mol] Such a cycle is given stoichiometrically by [kcal/g-mol]

$$
\left.\begin{array}{ll}
\Sigma a_{k} A_{k} \longrightarrow \Sigma b_{k} B_{k} & T=T_{1} \\
\Sigma b_{k} B_{k} \longrightarrow \Sigma a_{k} A_{k} & T=T_{2}
\end{array}\right\}
$$

where the former is the endothermic reaction and the latter is the exothermic reaction, i.e.,

$$
\left.\begin{array}{l}
\Delta H_{1}>0 \\
\Delta H_{2}=-\Delta H_{1}<0
\end{array}\right\}
$$

Assuming that $\Delta H$ and $\Delta S$ are constant and there is no phase change of chemical substances in a given temperature range, the change of free energy of both reactions are given by

$$
\begin{gathered}
\Delta G_{1}=\Delta H_{1}-T_{1} \Delta S_{1} \\
\Delta G_{2}=\Delta H_{2}-T_{2} \Delta S_{2}=-\Delta H_{1}+T_{2} \Delta S_{1}
\end{gathered}
$$

Combination of Eqs. (3) and (4) leads to

$$
\begin{aligned}
\Delta G_{1}+\Delta G_{2} & =\left(T_{2}-T_{1}\right) \Delta S_{1} \\
& =\left(T_{2}-T_{1}\right)\left(\Delta H_{1}-\Delta G_{1}\right) / T_{1}
\end{aligned}
$$

Since it is desirable that $\Delta G$ has a negative value for a promising reaction to take place, the following relation must be satisfied.

$$
T_{1} \geq T_{2}
$$

Equation (6) means that we can't level up thermal energy by the two-step cycle, though the concept of EVA-ADAM is very interesting.

Let us consider, next, a three-step cycle. This cycle must include two reactions, one the endo- 
thermic reaction occurring at lower temperatures and the other the exothermic reaction occurring at higher temperatures. These conditions are expressed as

$$
\begin{aligned}
& \Delta H_{1}<0, \Delta H_{2}>0 \text { and } \Delta H_{3} \gtrless 0 \\
& T_{1}>T_{2}, T_{1}>T_{3}
\end{aligned}
$$

where subscript represents each reaction. This is the closed cycle. Therefore, we have

$$
\begin{aligned}
& \sum_{i=1}^{3} \Delta H_{i}=0 \\
& \sum_{i=1}^{3} \Delta S_{i}=0
\end{aligned}
$$

The temperature of each reaction should be selected to hold the equation given by

$$
\Delta G_{i}=\Delta H_{i}-T_{i} \Delta S_{i} \leqq 0
$$

Combination of Eqs. (7), (8), (9) and (10), then, becomes

$$
\begin{aligned}
\Delta H_{3} & \geqq-\left(T_{2} \Delta S_{2}+T_{1} \Delta S_{1}\right) \\
& \geqq \Delta S_{2}\left(T_{1}-T_{2}\right)+T_{1} \Delta H_{3} / T_{3} \\
\therefore \quad \Delta H_{3} & \leqq T_{3}\left(T_{1}-T_{2}\right) \Delta S_{2} /\left(T_{3}-T_{1}\right) \leqq 0
\end{aligned}
$$

And following condition can be obtained (see Appendix).

$$
T_{2} \geqq T_{3}
$$

The relationship among these reactions is illustrated by Fig. 1. Now, low-level thermal energy will be absorbed by the endothermic reaction and finally recovered at higher temperatures through the exothermic reaction.

Three-step cycle is represented simply by

$$
\begin{array}{rll}
\text { (i) } & A+B \stackrel{T_{1}}{\longrightarrow} C+D & \Delta H_{1}<0 \\
\text { (ii) } & C+E \stackrel{T_{2}}{\longrightarrow} B+F & \Delta H_{2}>0 \\
\text { (iii) } & F+D \stackrel{T_{3}}{\longrightarrow} E+A & \Delta H_{3}<0
\end{array}
$$

Figure 2 shows the flow of chemical substances of this cycle. Assuming that there is no phase change of chemical substances, $\Delta H$ and $\Delta S$ are given by the function of temperature expressed as

$$
\left.\begin{array}{l}
\Delta H_{i}(T)=\Delta H_{i}\left(T_{0}\right)+\int_{T_{0}}^{T} \Delta C_{p i}(T) d T \\
\Delta S_{i}(T)=\Delta S_{i}\left(T_{0}\right)+\int_{T_{0}}^{T} \frac{\Delta C_{p i}(T)}{T} d T
\end{array}\right\}
$$

where $C_{p i}$ represents the specific heat at constant pressure. The input heat absorbed by the reaction (ii) and output heat recovered by the reaction (i) and (iii) are given respectively by

$$
\begin{aligned}
& Q_{\text {in }}=\Delta H_{2}\left(T_{2}\right)+Q_{\text {ex }} \\
& Q_{\text {out }}=-\Delta H_{1}\left(T_{1}\right)-\Delta H_{3}\left(T_{3}\right)
\end{aligned}
$$

where $Q_{e x}$ represents the amount of heat absorbed by exchange from one chemical substance to the other. Then, $Q_{\text {ex }}$ is calculated from the equation

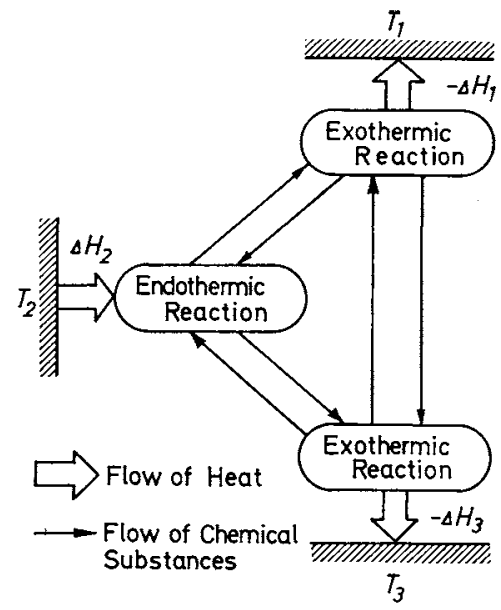

Fig. 1 Relationship among three reactions

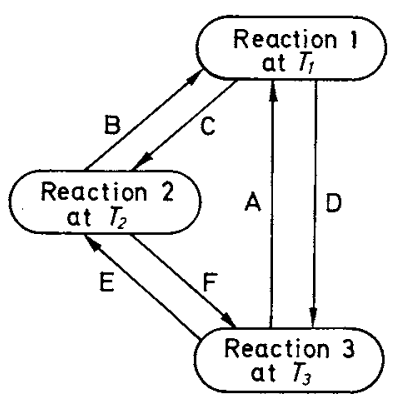

Fig. 2 Flow of chemical substances

$$
\begin{aligned}
Q_{\mathrm{ex}}= & \int_{T_{3}}^{T_{1}} C_{A} d T+\int_{T_{1}}^{T_{3}} C_{D} d T+\int_{T_{2}}^{T_{1}} C_{B} d T+\int_{T_{1}}^{T_{2}} C_{C} d T \\
& +\int_{T_{3}}^{T_{2}} C_{E} d T+\int_{T_{2}}^{T_{3}} C_{F} d T \\
= & -\int_{T_{2}}^{T_{1}} \Delta C_{p 1} d T+\int_{T_{3}}^{T_{2}} \Delta C_{p 3} d T
\end{aligned}
$$

Maximum work is given by the product of heat absorbed and Carnot efficiencies. So, the maximum works to be done by the heat, $Q_{\text {in }}$ and $Q_{\text {out }}$, are given respectively by

$$
\begin{aligned}
& W_{\text {in }}=\Delta H_{2}\left(T_{2}\right) \frac{T_{2}-T_{0}}{T_{2}}+W_{\mathrm{ex}} \\
& W_{\text {out }}=-\Delta H_{1}\left(T_{1}\right) \frac{T_{1}-T_{0}}{T_{1}}-\Delta H_{3}\left(T_{3}\right) \frac{T_{3}-T_{0}}{T_{3}}
\end{aligned}
$$

$W_{\text {ex }}$ is the maximum work done by $Q_{\text {ex }}$ and given by

$$
W_{\mathrm{ex}}=-\int_{T_{2}}^{T_{1} 1} \Delta C_{p 1} \frac{T-T_{0}}{T} d T+\int_{T_{3}}^{T_{2}} \Delta C_{p 3} \frac{T-T_{0}}{T} d T
$$

The difference between $W_{\text {in }}$ and $W_{\text {out }}$, therefore, is obtained by

$$
\begin{aligned}
W_{\mathrm{in}}-W_{\mathrm{out}} & =\sum_{i=1}^{3} \Delta H_{i}\left(T_{i}\right) \frac{T_{i}-T_{0}}{T_{i}}+W_{\mathrm{ex}} \\
& \geqq \sum_{i=1}^{3}\left\{\Delta H_{i}\left(T_{i}\right)-T_{0} \Delta S_{i}\left(T_{i}\right)\right\}+W_{\mathrm{ex}} \\
& =\sum_{i=1}^{3} \Delta H_{i}\left(T_{0}\right)+\sum_{i=1}^{3} \int_{T_{0}}^{T_{i}} \Delta C_{p_{i}} d T
\end{aligned}
$$




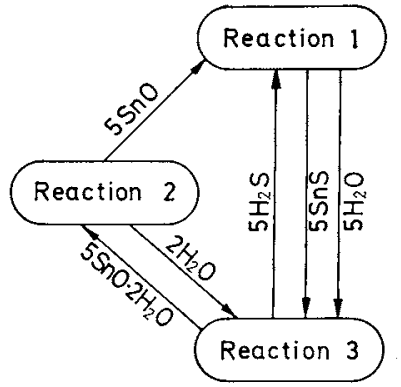

Fig. 3 Flow of chemical substances of the $\Delta-1$

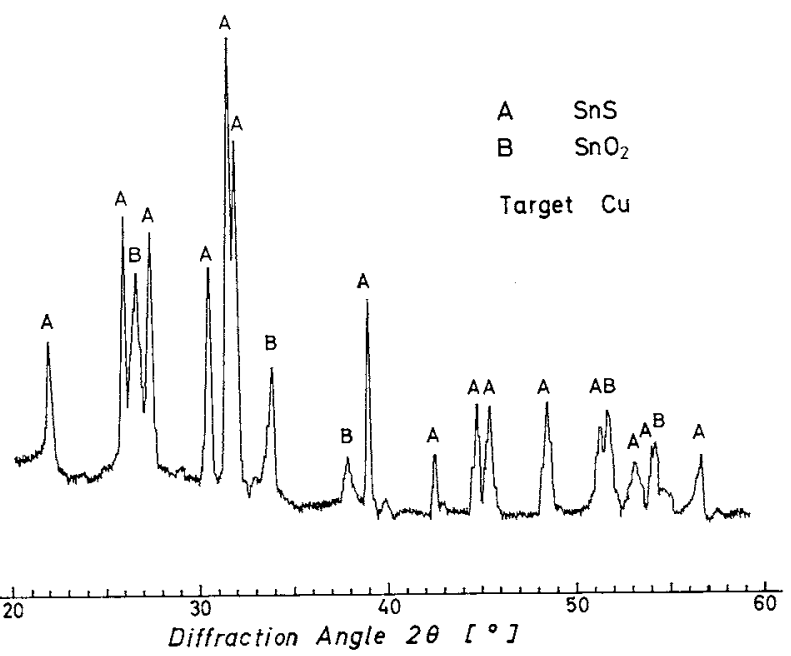

Fig. 4 X-ray diagram of products in reaction 1

$$
\begin{aligned}
& +T_{0}\left\{\sum_{i=1}^{3} \Delta S_{i}\left(T_{0}\right)\right. \\
& \left.-\sum_{i=1}^{3} \int_{T_{0}}^{T_{i}} \frac{\Delta C_{p i}}{T} d T\right\}+W_{\mathrm{ex}} \\
= & \int_{T_{0}}^{T_{1}} \Delta C_{p 1} \frac{T-T_{0}}{T} d T+\int_{T_{0}}^{T_{2}} \Delta C_{p 2} \frac{T-T_{0}}{T} d T \\
& +\int_{T_{0}}^{T_{3}} \Delta C_{p 3} \frac{T-T_{0}}{T} d T+W_{\mathrm{ex}} \\
= & -\int_{T_{2}}^{T_{1}} \Delta C_{p 1} \frac{T-T_{0}}{T} d T \\
& +\int_{T_{3}}^{T_{2}} \Delta C_{p 3}-T-T_{0}-T^{--} d T+W_{\mathrm{ex}} \\
= & 0
\end{aligned}
$$

Thus, we have

$$
W_{\text {in }} \geqq W_{\text {out }}
$$

Therefore, the maximum work done by the input heat is always greater than that done by the output heat. No energy is newly produced by the chemical cycle, and therefore the chemical heat pump is concistent with the statement of law of thermodynamics.

\section{Proposed Cycle}

An example of possible cycles is given by:

(i) $5 \mathrm{SnO}(\mathrm{s})+5 \mathrm{H}_{2} \mathrm{~S}(\mathrm{~g}) \stackrel{T=773}{\rightarrow} 5 \mathrm{SnS}(\mathrm{s})+5 \mathrm{H}_{2} \mathrm{O}(\mathrm{g})$ (ii) $5 \mathrm{SnO} \cdot 2 \mathrm{H}_{2} \mathrm{O}(\mathrm{s}) \stackrel{T=473}{\rightarrow} 5 \mathrm{SnO}(\mathrm{s})+2 \mathrm{H}_{2} \mathrm{O}(\mathrm{g})$

(iii) $5 \mathrm{SnS}(\mathrm{s})+7 \mathrm{H}_{2} \mathrm{O}(\mathrm{g})^{\stackrel{T}{ }=423} \rightarrow 5 \mathrm{H}_{2} \mathrm{~S}(\mathrm{~g})$ $+5 \mathrm{SnO} \cdot 2 \mathrm{H}_{2} \mathrm{O}(\mathrm{s})$

where $\Delta H_{1}=-50.2, \Delta H_{2}=60.0$ and $\Delta H_{3}=-8.0$.

Reaction (i) and (iii) are exothermic reactions and Reaction (ii) is an endothermic reaction. Thermodynamic data of these reactions were obtained by references ${ }^{1,4,6,7)}$. We call this cycle Triangle Process 1 (the abridged notation is $4-1$ ). The flow of chemical substances of this cycle is shown by Fig. 3 .

\section{Experimental}

Various experiments were carried out to check whether reactions consisting $\Delta-1$ actually take place or not. The reaction (i) was investigated as follows. A small quartz basket containing $1.53 \mathrm{~g} \mathrm{SnO}$ powder was hung in a quartz tube reactor and heated to $470^{\circ} \mathrm{C}$ in a stream of nitrogen. Nitrogen was then replaced to $\mathrm{H}_{2} \mathrm{~S}$ gas. Production of $\mathrm{SnS}$ was checked. by the X-ray diffraction of reacted powder. The chart is shown in Fig. 4.

Thermogravimetrical test for the reaction (ii) was carried out and the rapid weight change of Tin (II) oxide hydrate sample was found in the stream of Nitrogen at $200^{\circ} \mathrm{C}$. Donaldson and Moser $^{2}$ also reported the smooth progress of this dehydration.

The experiment of reaction (iii) was carried out similarly to reaction (i). A mixture of nitrogen and water $\left(\mathrm{N}_{2} 54 \%, \mathrm{H}_{2} \mathrm{O} 46 \%\right.$ was made to pass at $2.7 \mathrm{cc} / \mathrm{sec}$ through a packed bed of $\mathrm{SnS}$ whose temperature was kept at $150^{\circ} \mathrm{C}$. Concentration of $\mathrm{H}_{2} \mathrm{~S}$ was measured at the outlet of the reactor. Its values fluctuated between 100 and $400 \mathrm{ppm}$. The production of $5 \mathrm{SnO} \cdot 2 \mathrm{H}_{2} \mathrm{O}$ was identified in the X-ray chart of solid products.

\section{Discussion}

Thermal efficiency is an important factor for the evaluation of chemical heat pump. The efficiency is defined by the ratio of energy $E_{\text {out }}$ obtained from the cycle to the total energy $E_{\mathrm{in}}$ required for its operation. Both values $E_{\text {out }}$ and $E_{\text {in }}$ for the $\Delta-1$ are given by

$$
\begin{aligned}
& E_{\text {out }}=-\Delta H_{1}-\left(Q_{\mathrm{SnO}}+Q_{\mathrm{H}_{2} \mathrm{~S}}\right)\left(1-\eta_{\mathrm{ex}}\right) \\
& E_{\mathrm{in}}=\Delta H_{2}+Q_{5 \mathrm{Sno} \cdot 2 \mathrm{H}_{2} \mathrm{O}}\left(1-\eta_{\mathrm{ex}}\right)+W / \eta_{Q W}
\end{aligned}
$$

$Q_{\mathrm{SnO} O}, Q_{\mathrm{H}_{2} \mathrm{~S}}$ and $Q_{5 \mathrm{SnO} \cdot 2 \mathrm{H}_{2} \mathrm{O}}$ represent thermal energies necessary for heating up each chemical substances to designated temperatures and were calculated from data of heat capacities. $W$ represents the work necessary for the operation shown in Fig. 5.

In appearance the chemical heat pump is a tower which is composed of three reactors arranged vertically. Each reactor corresponds to each reaction. 
Solid products fall down in sequence through three reactors and are recycled from the bottom reactor to the tower top by a compressor. On the other hand, separation and compression processes are associated with each reaction for gas reactants. There will be recycling of unreacted gas reactants and the flowrates must be set by compression in such a way that the stoichiometry of each chemical reaction is achieved.

Therefore, the procedure to calculate the value of $W$ is as follows. First, assume the conversion for a gas reactant. Then, obtain mol-fraction of each component from the equilibrium constant at the temperature shown by the chemical formula of $4-1$. Then, calculate both $W_{s}$ and $W_{p}$ by these values. The former symbol $W_{s}$ represents the theoretical work of separation required for recycling and is given by

$$
W_{s}=n R T \cdot \ln (1 / y)
$$

and the latter symbol $W_{p}$ represents theoretical work of compression given by

$$
W_{p}=n R T \cdot \ln \left(P^{\prime} / P\right)
$$

where $P$ and $P^{\prime}$ represent respectively operating pressure before and after compression.

Total amount of work is given by the summation of $W_{s}$ and $W_{p}$. In addition, the work for solid recycling must be accounted for. But an accurate estimate of this value is not available at present and in general, is relatively small in comparison with gas compression. Besides, $W$ is already overestimated since the separation of a gas mixture for reaction (iii) can be omitted. Therefore, the work for solid recycling was assumed to be negligible.

Thus, taking values 0.9 for $\eta_{\mathrm{ex}}$ and 0.4 for $\eta_{Q W}$ the efficiency $27 \%$ was obtained when conversion of gas reactants is assumed to be $30 \%$. This efficiency suggests that the chemical heat pump would be potentially competitive with other recovery methods such as the freon-turbine and the heat pump, though we assumed rather conservative value of conversion. Of course, refinement of efficiency must be done based on detailed engineering design. Such a practical implementation will require considerable additional $\mathrm{R} \& \mathrm{D}$ which is ongoing.

In this paper we only proposed the concept of a chemical heat pump and only showed one cycle named 4-1. However, search for other possible cycles have been conducted. Two other examples among them are shown as follows:

$$
\begin{aligned}
& \text { 4-2 }
\end{aligned}
$$

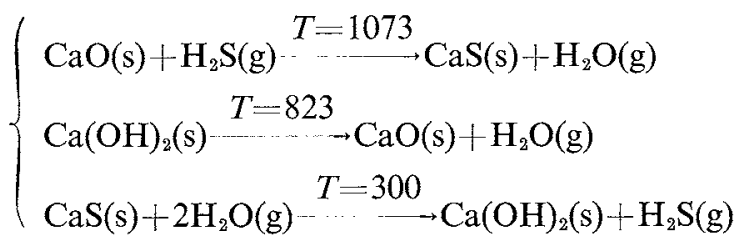

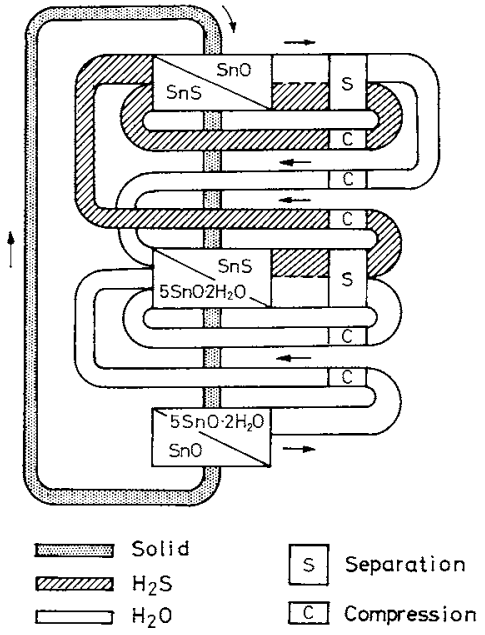

Fig. 5 Flowsheet for operation

where $\Delta H_{1}=-15.8, \Delta H_{2}=23.8$ and $\Delta H_{3}=-11.0$.

$4-3$

$$
\left\{\begin{array}{l}
\mathrm{CO}(\mathrm{g})+\mathrm{H}_{2} \mathrm{O}(\mathrm{g}) \stackrel{T=1073}{\rightarrow} \rightarrow \mathrm{CO}_{2}(\mathrm{~g})+\mathrm{H}_{2}(\mathrm{~g}) \\
\mathrm{CH}_{4}(\mathrm{~g})+\mathrm{H}_{2} \mathrm{O}(\mathrm{g}) \stackrel{T=873}{-} \rightarrow \mathrm{CO}(\mathrm{g})+3 \mathrm{H}_{2}(\mathrm{~g}) \\
4 \mathrm{H}_{2}(\mathrm{~g})+\mathrm{CO}_{2}(\mathrm{~g})-\stackrel{T=823}{\rightarrow} \rightarrow \mathrm{CH}_{4}(\mathrm{~g})+2 \mathrm{H}_{2} \mathrm{O}(\mathrm{g})
\end{array}\right.
$$

where $\Delta H_{1}=-8.2, \Delta H_{2}=53.6$ and $\Delta H_{3}=-44.6$.

Informations in detail of other cycles and kinetic data obtained by experiments will appear elsewhere.

\section{Conclusions}

A new method called "chemical heat pump" for recovering low-level thermal energy was proposed. It is a closed cycle and composed of three reactions, the low-level energy is absorbed at low temperatures and heated up to high temperatures by use of an exothermic reaction. Actual examples, Triangle Processes 1, 2 and 3, were shown and checked experimentally. The thermal efficiency was estimated to be $27 \%$ and therefore this method would be expected to have a great feasibility of industrial development.

Appendix

From Eq. (10) following relations can be obtained with respect to $i$ equal to 1 and 2 .

$$
\begin{aligned}
& \Delta H_{1}-T_{1} \Delta S_{1} \leqq 0 \\
& \Delta H_{2}-T_{2} \Delta S_{2} \leqq 0
\end{aligned}
$$

$\Delta S_{2}$ must be positive from Eq. (A-2) as $\Delta H_{2}$ is positive shown in Eq. (7). Rewriting of Eq. (A-2) becomes

$$
\Delta H_{2}-T_{1} \Delta S_{2}+\left(T_{1}-T_{2}\right) \Delta S_{2} \leqq 0
$$

Since the third term is positive, the first two terms must be negative, i.e.,

$$
\Delta H_{2}-T_{1} \Delta S_{2} \leqq 0
$$

Combination of Eqs. (A-1), (A-3), (8) and (9) gives

$$
\Delta H_{1}+\Delta H_{2}-T_{1}\left(\Delta S_{1}+\Delta S_{2}\right)=-\Delta H_{3}+T_{1} \Delta S_{3} \leqq 0
$$

Therefore we have

$$
\Delta S_{3} \leqq \Delta H_{3} / T_{1} \leqq 0
$$


On the other hand, $\Delta G_{1}\left(T_{2}\right)$ can be written by using Eqs. (8) and (9) as

$$
\begin{aligned}
\Delta G_{1}\left(T_{2}\right) & =\Delta H_{1}-\Delta T_{2} \Delta S_{1} \\
& =-\left(\Delta H_{2}-T_{2} \Delta S_{2}\right)-\left(\Delta H_{3}-T_{3} \Delta S_{3}\right)+\left(T_{2}-T_{3}\right) \Delta S_{3}
\end{aligned}
$$

The first two terms in right hand side are positive from Eq. (10) and $\Delta S_{3}$ is negative from Eq. (A-4). Therefore following relation must be given to be that $\Delta G_{1}\left(T_{2}\right)$ is negative.

$$
T_{2} \geq T_{3}
$$

\begin{tabular}{|c|c|}
\hline$A_{k}, B_{k}$ & $=$ chemical substances \\
\hline$a_{k}, b_{k}$ & $=$ stoichiometric coefficients \\
\hline$C_{p}$ & $=$ heat capacity \\
\hline$E_{\mathrm{in}}, E_{\mathrm{out}}$ & $\begin{array}{l}=\text { energy required and obtained, } \\
\text { respectively }\end{array}$ \\
\hline$\Delta G$ & $=$ change in standard free energy \\
\hline$\Delta H$ & $=$ change in standard enthalpy \\
\hline$P, P^{\prime}$ & $\begin{array}{l}=\text { pressure before and after compres } \\
\text { respectively }\end{array}$ \\
\hline$Q_{e x}$ & $=$ amount of heat exchanged \\
\hline$Q_{\text {in }}, Q_{\text {ott }}$ & $\begin{array}{l}=\text { heat required and obtained, } \\
\text { respectively }\end{array}$ \\
\hline$R$ & $=$ gas constant \\
\hline$\Delta S$ & $=$ change in standard entropy \\
\hline$T$ & $=$ absolute temperature \\
\hline$W$ & $=$ work necessary for operation \\
\hline$W_{\text {in }}, W_{\text {out }}$ & $\begin{aligned}= & \text { work required and obtained, } \\
& \text { respectively }\end{aligned}$ \\
\hline$W_{\mathrm{p}}$ & $=$ work necessary for compression \\
\hline$W_{\mathrm{s}}$ & $=$ work necessary for separation \\
\hline$y$ & $=$ molar fraction of gas reactant \\
\hline
\end{tabular}

\section{Nomenclature}

$[\mathrm{kcal} / \mathrm{g}-\mathrm{mol}]$

$$
\begin{array}{ll}
\eta & =\text { efficiency of cycle } \\
\eta_{\mathrm{ex}} & =\text { efficiency of heat exchange } \\
\eta_{Q W} & =\text { efficiency of transformation from } \\
& \text { heat to work }
\end{array}
$$

\section{Acknowledgments}

This work was partially supported by a grant-in-aid for scientific research of the Ministry of Education, Japan. K. Yoshida is also indebted to the Kawakami Memorial Foundation for its financial support.

$\langle$ Suffix $\rangle$

\section{Literature Cited}

1) Barin, I. and O. Knacke: "Thermochemical Properties of Inorganic Chemistry", Springer, Berlin (1973).

2) Donaldson, J. D., W. Moser and W. B. Simpson: J. Chem. Soc., 2, 839 (1961).

3) Kato, T.: Print of the 3rd Sym. on Energy, Science Council Japan, Tokyo (1976).

4) Kubaschewski, O. and E. L. Evans: "Metallurgical Thermochemistry", Pergamon Press, Oxford (1967).

5) Kugeler, K.: Annual Report of Nuclear Research Center, Jülich, p. 8 (1972).

6) Rossini, F. D., D. D. Wagman, W. H. Evans, S. Levine and I. Jaffee: "Selected Values of Chemical Thermodynamic Properties", Nat. Bur. Stand. (1952).

7) Stull, D. R. and H. Prophet: "JANAF Thermochemical Tables", 2nd Ed., Nat. Bur. Stand. (1971). 